\title{
New Perspectives on the End of Life
}

\author{
Ian Kerridge • Paul A. Komesaroff • \\ Malcolm Parker $\cdot$ Elizabeth Peter
}

Received: 11 July 2009 / Accepted: 16 July 2009 / Published online: 9 August 2009

(C) Springer Science + Business Media B.V. 2009

End of life concerns are a key area for ethics, law and health care. Much has been written about death and dying and there are many well-known and wellestablished positions about a range of issues, including: the understanding of death; the management of terminal illness, pain and suffering; the "value" of life; "killing and letting die", euthanasia and physicianassisted suicide; cultural and spiritual dimensions of death and dying; and the impact of "medical" considerations on death, such as organ donation and resource utilisation.

\footnotetext{
P. A. Komesaroff $(\bowtie)$

Monash University Centre for Ethics in Medicine and Society, Department of Medicine, The Alfred Hospital, Commercial Road,

Prahran, Victoria 3143, Australia

e-mail: paul.komesaroff@med.monash.edu.au

I. Kerridge

Centre for Values, Ethics and the Law in Medicine,

University of Sydney,

Sydney, Australia

e-mail: kerridge@med.usyd.edu.au

M. Parker

Faculty of Medicine, University of Queensland, Brisbane, Queensland, Australia

e-mail: m.parker@uq.edu.au

E. Peter

Faculty of Nursing, University of Toronto,

Toronto, Ontario, Canada

e-mail: elizabeth.peter@utoronto.ca
}

So is there anything new that can be said about the subject? Are there new positions that can be developed and new arguments that can be adduced? Are there old issues and controversies that need to be revisited? Are there new issues that need to be opened up? And are there new conceptual tools that can be brought to bear on old problems?

In this symposium we seek to provide new thinking, new data and new arguments about issues surrounding the end of life that continue to be of significant public and professional concern. We aim to highlight the diversity of thinking in this area of ethical discourse, including the importance of literary and other reflections not always considered central to the "bioethical project". It is our hope that the papers included demonstrate the value of perspectives arising in different cultural traditions and from different disciplinary perspectives, both by identifying new conceptual resources that might be applied to old problems and by raising the crucial problem of how modern-or postmodern - societies might accommodate widely differing, sometimes directly opposed, perspectives within a single political, legal and cultural context.

Charles Douglas provides a consequentialist examination of the distinction between "killing and letting die", arguing against the usual consequentialist view that the distinction is not morally relevant. The position that Douglas advances is valuable both because it demonstrates that new developments and new arguments are possible even within the ortho- 
doxy of bioethics and because it brings utilitarianism much closer to many of the opposing perspectives on decision-making at the end of life. Judith Rietjens and colleagues provide a comprehensive overview of empirical research conducted on euthanasia and physician-assisted suicide in the Netherlands over the past two decades. This paper adds significantly to an examination of the issues surrounding death and dying and illustrates how valuable empirical research can be in informing and enriching philosophical, legal and social discourse. As an example, much has been written about how liberalising laws relating to euthanasia may lead down a "slippery slope" to instances of involuntary killing of vulnerable people. However, the data presented by Rietjens show that that no such slope has come into existence as a result of the legalisation of euthanasia in the Netherlands, but that the process has remained controllable and appears to have filled a specific, if limited, gap in the medical management of terminally ill patients. In his review of the biography of Rodney Syme, Roger Magnusson further explores the risks and benefits associated with both permissive legislation and the prohibition of euthanasia and physician-assisted suicide. Magnusson's conclusion-that assistance in dying may be sympathetically regarded as an inherent component of palliative care-presents an important challenge to traditional accounts of ethics and law at the end of life. A slightly different approach is taken by Richard Huxtable who, in his analysis of "suicide tourism" in Europe, criticises liberal perspectives on the end of life that would allow euthanasia or physicianassisted suicide in countries where such legislation has popular and political support. Huxtable's paper reminds us that in a globalised world national legislation and moral norms surrounding death and dying may be either enriched or compromised by the movement of people and ideas.

The papers by Daniel Sinclair and James L. Nelson are concerned less with the "active management" of dying than with the broader meanings associated with death. Sinclair provides a rich account of some aspects of Jewish attitudes to death as they emerge from the Talmudic tradition. His paper provides a clear and accessible overview of Jewish approaches to death and dying and identifies some continuing controversies from within this faith tradition. He develops some concepts from a "liberal" perspective that resonate strongly with contemporary secular accounts of death and dying, such as that of "soft autonomy". Nelson provides a careful philosophical argument about the status of brain death in the setting of organ donation. His conclusion, that organ retrieval may be justified in certain circumstances, even where it directly results in death, is an important challenge to the "dead donor rule" and to deeply held medical and moral convictions regarding organ donation and transplantation.

Poems by Les Murray and Kevin Hart complement and complete the symposium. Although poetry is not normally considered a central part of the "bioethics literature", each of these poems says more about the complexity, profundity and subjectivity of dying and death than is possible in an academic manuscript. While each has its own focus-for example, the death of a father, the existential despair of dying and the "illness trajectory"-all speak to the reader about the meaning of health and illness, the awful and unsayable nature of loss and the certainty, and the solitude, of our own death. We are greatly indebted to Les Murray and Kevin Hart for agreeing to have their poems reproduced in this symposium. We feel that they show vividly that there are many ways to think about death and dying and that literary texts may greatly enrich philosophical and legal analysis as well as cultural discourses.

It is not our aim, and we do not anticipate, that these essays and poems will draw to a definitive conclusion any of the major debates about end of life issues in medicine and health care. But we do hope that they will generate further reflections as part of ongoing, fecund cultural and philosophical debates. 